\title{
LOW VOLTAGE GRID CONNECTED THREE-PHASE INVERTER CONTROL WITH HYBRID NEURO-FUZZY
}

\author{
Ndiaye El hadji Mbaye ${ }^{1, ~ *, ~ N d i a y e ~ A l p h o u s s e y n i ~}{ }^{1,2}$, Faye Mactar ${ }^{1,2}$ \\ ${ }^{1}$ Research team energetic system and efficiency, Alioune Diop University of Bambey \\ ${ }^{2}$ Laboratory of Water, Energy, Environment and Industrial Processes, ESP, S-10700, Dakar-Fann, Senegal. \\ *E-mail:elhadjimbave.ndiave@uadb.edu.sn,alphoussevni.ndiave@uadb.edu.sn,mactar.faye@uadb.edu.sn
}

\section{INFOS SUR L'A R T I C L E}

\section{Historique de l'article:}

Reçu le: 26 novembre 2020

Réçu en format revisé le : 17 février 2021

Accepté le : 20 février 2021

Keywords : Low Voltage Grid, ANFIS,

three-phase inverter, Modified PID, THD.

\begin{abstract}
A B S T R A C T
In this paper, an Adaptive Neuro Fuzzy Inference System (ANFIS) and Modified Proportional Integral Derivate (MPID) are used for respectively DClink voltage regulation and grid currents regulation for grid connected threephase inverter. The main purpose of this work is to reduce the fluctuation on DC-link voltage and the Total Harmonic Distortion (THD) on the injected currents. Indeed, the use of Proportional-Integral (PI) controller cannot achieve these objectives due to their disturbances sensitivity problem and limited regulation bandwidth. To avoid these problems, an ANFIS regulator has been designed. Results show that ANFIS has a very short response time (Rt) $0.097 \mathrm{~s}$ with no overshoot (D).
\end{abstract}

Nomenclature
L1 $(\mathrm{mH})$
L2 $(\mathrm{mH})$
i1 $(\mathrm{A})$
i2 $(\mathrm{A})$
$\mathrm{C} 2(\mu \mathrm{F})$
Vdc $(\mathrm{V})$
Fc $(\mathrm{kHz})$
$\alpha$
L $(\mathrm{mH})$
$\mathrm{s}$
$\mathrm{Kp}$
$\mathrm{Ki}\left(\mathrm{s}^{-1)}\right.$
$\mathrm{Kd}(\mathrm{s})$
$\tau(\mathrm{s})$
$\mathrm{Ia}, \mathrm{Ib}, \mathrm{Ic}(\mathrm{A})$
Vd,q $(\mathrm{V})$
Va, Vb, Vc $(\mathrm{V})$
Id,Iq $(\mathrm{A})$
$\mathrm{Sa}, \mathrm{Sb}, \mathrm{Sc}$
V $\alpha, \beta(\mathrm{A})$
$\mathrm{Z}(\Omega)$
m
C $(\mu \mathrm{F})$
$\mathrm{R}_{\mathrm{f}}(\Omega)$
$\theta \mathrm{r}(\mathrm{rad})$
$\theta \mathrm{r}(\mathrm{rad})$
V $(\mathrm{V})$
w $(\mathrm{rad} / \mathrm{s})$

\section{INTRODUCTION}

The world continues to be faced with a significant demand for energy. The fossil resources which occupy the first place in the production of electricity at the world level are in addition to being non-renewable, harmful for the environment [1]. The search for a solution launched several years ago promotes the use of renewable energies such as Photovoltaic Solar Energy (PSE). It is clean
Inverter side filter

Grid side filter

Inverter side current

Grid side current

Boost output capacity

DC link voltage

Frequency of switching the Mosfet

Duty cycle

Inductance

Variable of Laplace

Proportional gain

Integral gain

Derivative gain

Constant time

Output inverter current

Active and reactive voltage

Simple voltages of the inverter

Active and reactive current

Switching states of the inverter

Voltage in Concordia base

Grid impedance

Modulation indice

Capacitance of the LCL filter

Damping resistance of the LCL filter

Output angle of the PLL

Grid angle

Nominal simple voltage of the grid

Grid pulsation

energy. Its exploitation is safe for humanity. Its limits are linked to its power losses due to the intermittence of the solar source and the low efficiency of the photovoltaic cell (PV). It is therefore important to optimize the power [2]. Due to changing environmental conditions, the operating point of the PV array changes, which affects the output power of the PV array. The overall efficiency of the operation will be reduced. Maximum Power Point 
Tracking (MPPT) technics are used to extract the maximum output power. The boost converter serves the purpose of voltage regulation along with the voltage boost which is required to isolate the AC part from the PV side. In order to capture the optimal PV power, several MPPT algorithms are designed around the DC-DC converter [3][5]. These algorithms differed by their complexities and performances but they required the measure of PV current and voltage [6]. The principal algorithms are perturbation and observation $(\mathrm{P \& O})$, incremental conductance $\mathrm{InC}$, fuzzy logic (FL) [7].

PSE should operate in grid-connected operation mode and islanding operation mode. The grid-connected inverter play an important part in the Distributed Generation System (DGS) [8]. The penetration of PSE into the distribution system at a medium and low-voltage level poses various challenges to maintaining the power quality and operation integrity. The grid regulations such as antiislanding and low-voltage ride through are imposed on the PV system to ensure the desired control during unbalanced conditions. It is extremely important to identify such events and take proper action to minimize the damage to the PV generator and cause less harm to the interconnected loads and grid. The inverter control can be designed to limit the current and reduce the active power oscillations during a fault. The conventional method of the inverter control contains the outer loop voltage and the inner current control loop which regulate respectively the output inverter currents and the DC-link voltage. The outer loop regulator compares the DC-bus voltage in the link capacitor with a voltage reference. Most of the researchers who worked on the controls of the three-phase inverter connected to the grid used conventional correctors for the current and voltage regulation loops [9]-[11]. These correctors are for the most part the PI and the PID and they are used in the Park base but all require exact linear mathematical models. Their limits appear during weather variations. Strong disturbances on the grid side also reveal their limit. They cannot follow these disturbances with low response times. This is then one of the reasons why adaptive correctors are used more and more. With a very great capacity for learning and adaptation, they can anticipate any disruptions [12][13]-[16]. The techniques based on Artificial Intelligence (AI) algorithms are the most used. Among theme, Artificial Neural Networks (ANN) attracted more applications in power electronics systems due to its fast dynamic response without disturbing the stability of the system over a wide range of operation [17][9].

ANN can learn from data. However, understanding the knowledge learned by neural networks has been difficult. To be more specific, it is usually difficult to develop an insight about the meaning associated with each neuron and each weight. In contrast, fuzzy rule based models are easy to be understood because it uses linguistic terms and the structure of fuzzy rules. Unlike neural networks, however, FL by itself cannot learn. The learning and identification of FL systems need to adopt techniques from other areas, such as statistics, system identification. Since neural networks can learn, it is natural to merge these two techniques. The Adaptive Neuro Fuzzy Inference System (ANFIS) coordinates ANN system and FL [18]-[20]. The ANFIS method gives good results compared to the methods mentioned above [21]. Its advantage is that it allows to integrate the knowledge that the user has on the inputs and outputs. In [22], authors present an improved performance of coordinated control scheme for exchanging power between a single phase electrical grid and battery energy storage system (BESS) using ANFIS. The ANFIS regulator is used to regulate the voltage of the DC-link. They find that ANFIS has the best performance compared to the PI regulator. In [23], design, simulation and implementation of a dSPACE based grid interactive voltage source inverter are proposed. This single phase inverter has ANFIS controller for DC-link voltage and grid current. Compared to PI, results show that ANFIS has the lowest response time and the lowest THD.

These authors used ANFIS for the regulation of single phase systems where regulation is very complex with PI or PID regulators.

The objective of this paper is to regulate the DC link voltage and Low Voltage Grid (LVG) currents by using respectively ANFIS and MPID in three-phase system. The aim of this command is to inject energy into the grid at unity power factor and a current with low harmonic distortion.

\section{MATERIALS AND METHODS}

The main objective of the control is to convert DC power from PV generator to AC power feeding to the grid. Fig.1 presents the proposed architecture of the grid connected system and its control. This system is composed of two parts: a continuous (DC) part and an alternative part (AC). The DC part is the energy from the PV and the AC is composed by the inverter, the LVG and is controlled by a balanced active and reactive power control. The outputs of current controller are connected together to those of voltage controller, in order to prevent a sudden change of the outputs of both controllers during the transfer instant. A Phase Locked Loop (PLL) controller is used to synchronize the phase of inverter output voltage with a grid voltage or generate a desired inverter voltage. In this work, only the AC part is studied. The MPPT command will not be presented. 


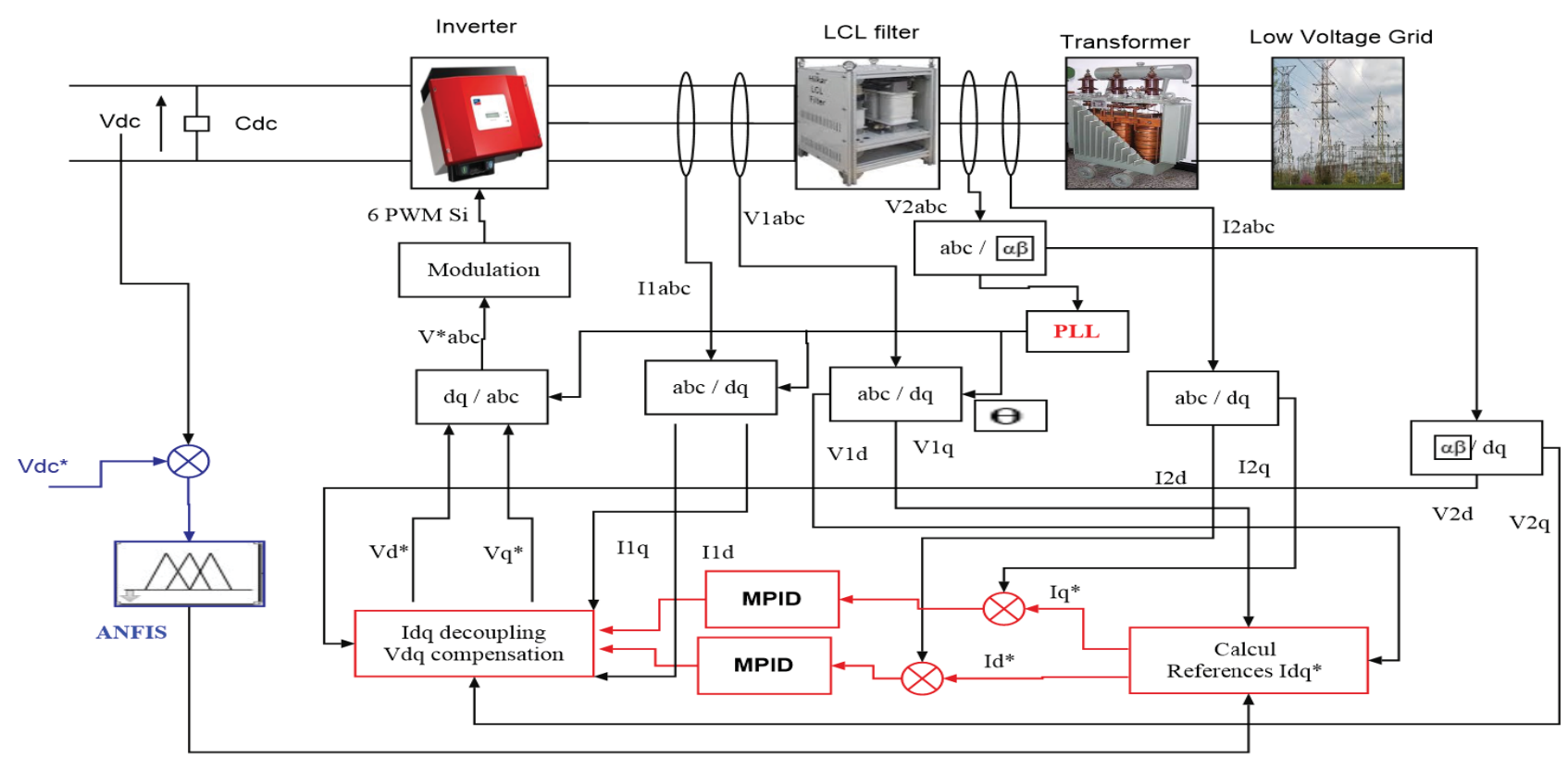

Fig.1. Diagram of the grid connected to PV system and its control loop

\subsection{Modeling of the AC part}

\subsubsection{Modeling of the three-phase inverter}

The inverter is the main device of the grid connected solar PV system and its mission is to convert the generate dc voltage into suitable as currents to be fed into the threephase low voltage utility grid. It is modeled by equation (1).

$V_{x o}=\frac{V_{d c}}{2}\left(2 S_{x 1}-1\right)$

With $\mathrm{x}=\mathrm{a}, \mathrm{b}, \mathrm{c}$.

The complex form of the voltage is given by the equation (2).

$V=V_{a} e^{i 0}+V_{b} e^{-\frac{2 \pi}{3} j}+V_{c} e^{\frac{2 \pi}{3} j}$

\subsubsection{Modeling of LCL filter}

In this part, we make the following hypotheses:

$$
\begin{array}{ll}
- & V_{x n}=V_{1} \\
- & L_{2}=L_{2 f}+L_{g} \\
- & V_{g}=V_{2}
\end{array}
$$

- The internal resistances of the filter are neglected

$\mathrm{V}_{1}$ : filter side voltage;

$\mathrm{V}_{2}$ : grid side voltage;

$\mathrm{L}_{2}$ : grid side inductance;

$\mathrm{L}_{2 \mathrm{f}}$ : Filter side inductance;

$\mathrm{L}_{\mathrm{g}}$ : grid inductance.

The LCL filter is described as follow in equation (3).

$$
\left\{\begin{array}{l}
i_{1}(s)=\frac{V_{1}(s)-V C_{f}(s)}{s L_{1}+r_{1}} \\
i_{2}(s)=\frac{V_{C_{f}}(s)-V_{2}(s)}{s L_{2}+r_{2}} \\
i_{C_{f}}(s)=\frac{s L_{1}+r_{1}}{r_{f}+\frac{1}{s C_{f}}} i_{2}(s)
\end{array}\right.
$$

By opposing that the utility grid voltage is stable, we will only be interested in a single phase and thus represents the diagram of the single-phase filter and the following.

\subsubsection{Modeling of three-phase transformer and $L V G$}

In this case, the transformer is used to switch to medium voltage (V1) to low voltage (V2).

The transformation ratio is written as follows by equation (4):

$$
m=\frac{V_{s e}}{V_{2}}=\frac{i_{2}}{i_{s e}}
$$

The conservation of the power between the primary and the secondary makes it possible to write the following relation given by equation (5).

$V_{2} i_{2}=V_{s e} i_{s e}$

We thus obtain the mathematical model of the impedance of the LVG given by the equation (6).

$Z_{R}=\sqrt{R_{R}^{2}+\left(w L_{R}\right)^{2}}$

\subsection{Control of the three-phase inverter}

To learn the ANFIS system, a database is created with the MPID. In this base, ANFIS receives the error between the DC link voltage and the reference voltage. Its output is the active reference current. The voltage loop regulation consist of an ANFIS controller which is adopted to avoid stationary dc-link voltage and to provide the active reference current. The outer loop compares the dc bus 
voltage with a voltage reference (Fig.2). The inner control loop (Fig.3) uses two controllers to regulate the d-q or the $\alpha \beta$ components of the line currents allowing the synchronization of the three-phase inverter line currents with the LVG. In the case a MPID control is used to regulate the $\mathrm{d}-\mathrm{q}$ components of the inverter currents. The PLL controller based on the $\mathrm{p}$-q theory, which is used to synchronize the phase of inverter output voltage with a grid voltage at the grid-connected operation or generate a desired inverter output voltage at the islanding operation. Two feedback signals are obtained by the cosine and sine of the PLL output angle $\theta$ (Fig.4). The commanded voltages $\mathrm{V}_{\mathrm{d}}$ and $\mathrm{V}_{\mathrm{q}}$ are present in the rotating reference frame, which needs to be converted into abc voltages using the back-reference frame transformation conversion process. The conversion from dq components to $\alpha \beta$ can be achieved using equation (7).

$\left(\begin{array}{c}V_{\alpha} \\ V_{\beta}\end{array}\right)=\left(\begin{array}{cc}\sin \theta & \cos \theta \\ \cos \theta & -\sin \theta\end{array}\right)\left(\begin{array}{l}V_{d} \\ V_{q}\end{array}\right)$

After obtaining the stationary reference frame components, the three-phase components are calculated using equations (8).

$\left\{\begin{array}{l}V_{a}=V_{\alpha} \\ V_{b}=-\frac{V_{\alpha}}{2}-\frac{\sqrt{3}}{2} V_{\beta} \\ V_{c}=-\frac{V_{\alpha}}{2}+\frac{\sqrt{3}}{2} V_{\beta}\end{array}\right.$

The modulating signal drives the PWM of the inverter to obtain the desired voltage at the respective pole of the inverter. The gating signal for each three-pole of the inverter is obtained using equation (9). The transfer functions of DC link regulation, current regulation loop and PLL loop are respectively given by equations (10), (11) and (12).

$S_{a, b, c}=\frac{2 V_{a b c}}{V_{d c}}$

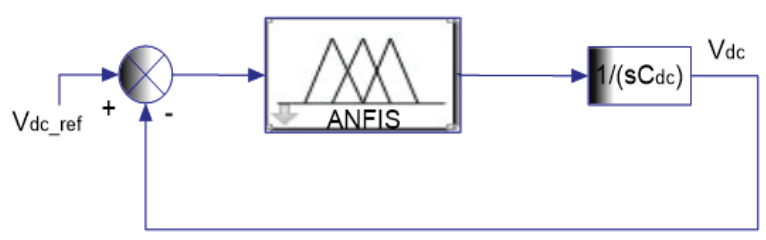

Fig.2. DC link voltage regulation loop

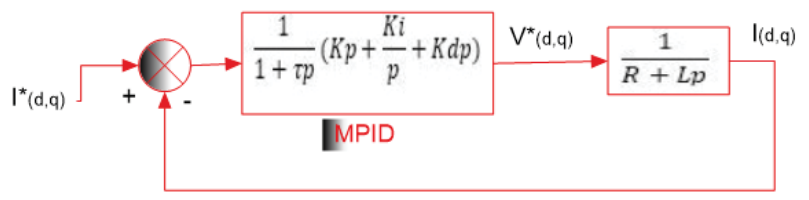

Fig.3. Current regulation loop

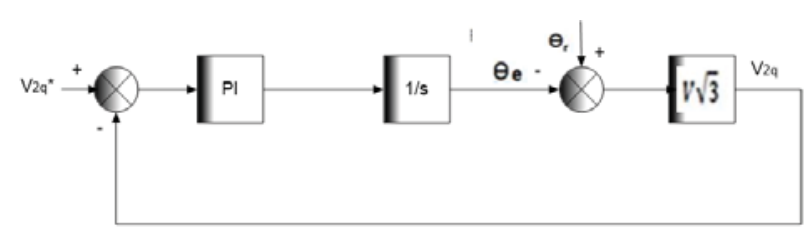

Fig.4. PLL loop
$F(s)=\frac{C_{d c} K_{p 1} s+\frac{K_{i 1}}{s}}{s^{2}+s K_{p 1}+\frac{K_{i 1}}{C_{d c}}}$

$G(s)=\frac{\frac{s K_{p 2}+K_{i 2}}{L_{1}}}{s^{2}+\left(\frac{s K_{p 2}}{L_{1}}\right)+\frac{K_{i 2}}{L_{1}}}$

$H(s)=-V \sqrt{3} \frac{s K_{p 3}+K_{i 3}}{s^{2}-V \sqrt{3} s K_{p 3}-V \sqrt{3} K_{i 3}}$

\section{RESULTS AND DISCUSSION}

The system under consideration is modeled and simulated under Matlab/Simulink environment. The physical system parameters used in this work are presented in Table 1.

Table 1. System parameters

\begin{tabular}{|l|l|}
\hline Parameters & Values \\
\hline Max PVG voltage & $423 \mathrm{~V}$ \\
\hline DC bus voltage & $500 \mathrm{~V}$ \\
\hline Max PVG current & $14.90 \mathrm{~A}$ \\
\hline Current of charge & $7.45 \mathrm{~A}$ \\
\hline Max PVG power & $6.44 \mathrm{~kW}$ \\
\hline Boost input capacity & $8.62 \mu \mathrm{F}$ \\
\hline Boost Inductance & $28.99 \mathrm{mH}$ \\
\hline Boost output capacity & $4.31 \mu \mathrm{F}$ \\
\hline Boost converter switching frequency & $10 \mathrm{kHz}$ \\
\hline Capacitance of the LCL filter $\left(\mathrm{C}_{\mathrm{f}}\right)$ & $15 \mu \mathrm{F}$ \\
\hline Capacitance damping resistance $\left(\mathrm{R}_{\mathrm{f}}\right)$ & $2 \Omega$ \\
\hline Inverter side filter $(\mathrm{L} 1)$ & $3.5 \mathrm{mH}$ \\
\hline Grid side filter $(\mathrm{L} 2)$ & $4.5 \mathrm{mH}$ \\
\hline Inverter switching frequency & $20 \mathrm{kHz}$ \\
\hline Grid Voltage & $220 \mathrm{~V}$ \\
\hline
\end{tabular}

The input parameters of the study system are shown in the Fig.5. These are ambient temperature and solar insolation due to their impact on the production of solar PV energy. Fig.6 shows the corrected DC-link voltage with the ANFIS regulator as a function of a $500 \mathrm{~V}$ reference voltage. This voltage must be kept constant around its reference value whatever the variations at the input of the system. ANFIS regulator has a very short response time (Rt) $0.097 \mathrm{~s}$ with no overshoot (D) and a very short rise time $\left(4.306 .10^{-3} \mathrm{~s}\right)$. Also, from the point of view of precision and stability, the ANFIS is in front. This is justified by the performance and robustness of ANFIS. The injected active and reactive power from the inverter are presented in Fig.7. The reactive power injection is zero, due to the unity power factor (UPF) condition. The power injected into the grid depends on the input parameters of the PV system: irradiation and temperature. In Fig. 8 it can be seen that current and voltage of the LVG are in phase. The peak value of the injected current into the grid is approximately $15 \mathrm{~A}$. The frequency spectrum of the LVG current at phase 1 using ANFIS is shown in Fig.9. Such a low THD $(0.85 \%)$, which complies with the IEEE standards (THD less than 5\%), shows that the energy injected into the grid 
is of good quality. The proposed controller design can operate in UPF mode or active power injection mode, as presented in these figures. It validates the grid regulation compliance in connection and reactive power injection requirement.

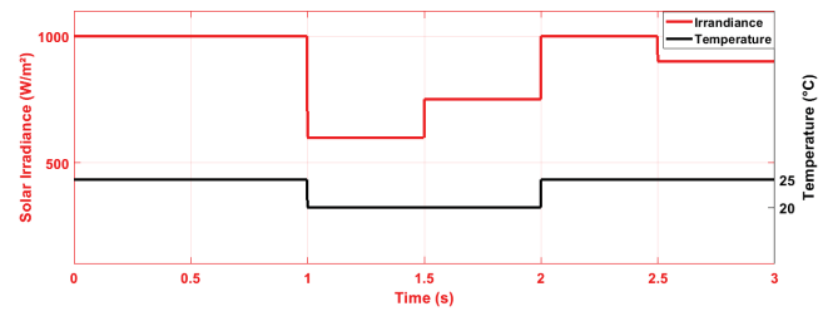

Fig.5. Sun insolation and ambient temperature

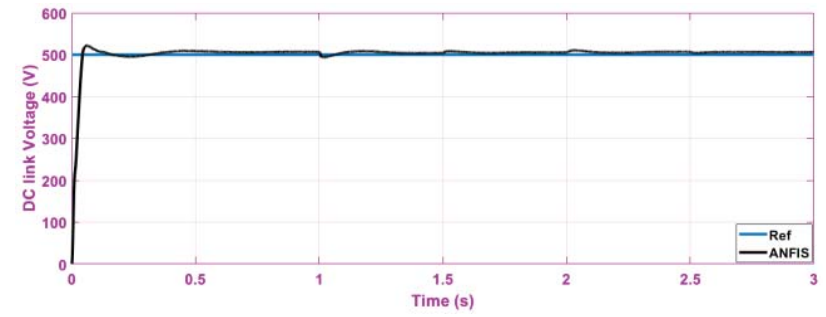

Fig.6. DC link voltage with ANFIS regulator

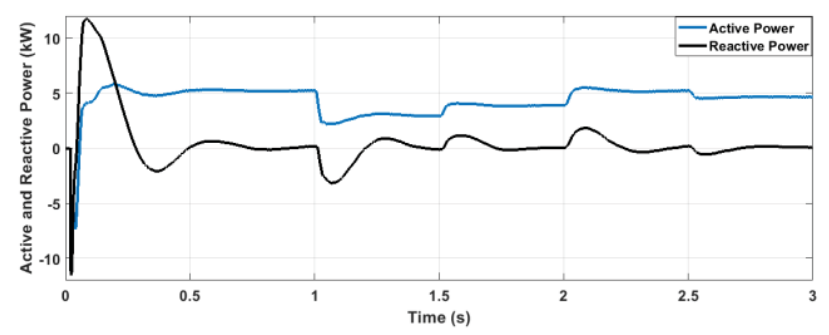

Fig.7. Active and reactive power injected into the $L V G$

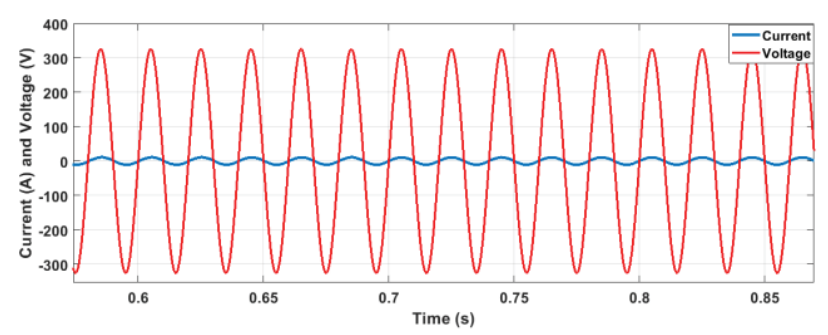

Fig.8. Current and voltage of the $L V G$

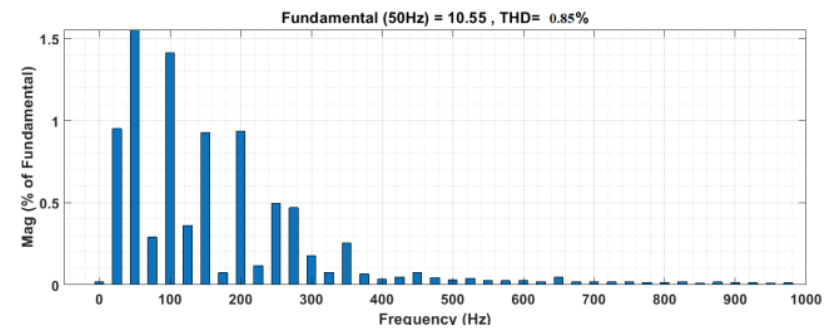

Fig.9. THD of current when using ANFIS for voltage regulation
The robustness study of the ANFIS corrector is presented in Table 2.

Table 2. Robustness criteria

\begin{tabular}{|l|c|c|c|}
\hline Criteria & Rt $(\mathrm{s})$ & $\mathrm{D}(\%)$ & RMSE \\
\hline ANFIS & 0.097 & 0 & 1.09 \\
\hline
\end{tabular}

The results obtained in this work are compared with those presented in [10] which the authors used an MPID regulator to regulate the DC-link voltage. The comparison results show that the ANFIS regulator performs better than the MPID regulator. The THD and response times are $0.85 \%$ and $0.097 \mathrm{~s}$ and $2.39 \%$ and $0.4 \mathrm{~s}$ respectively for ANFIS and MPID.

\section{CONCLUSION}

The AC-stage three-phase grid-connected PV system is studied thoroughly in this work. The complete modeling is presented in steps for the switching model of a single PV system. The inverter controller is designed using the ANFIS and MPID correctors. The designed controller injects the balanced sinusoidal current into the grid during $\mathrm{LVG}$, and it has some ripple left over due to the presence of a small ripple. The most important contribution of this work is the designing of ANFIS for DC link voltage regulation. Currents are injected with a low THD of $0.85 \%$.

\section{ACKNOWLEDGEMENTS.}

The authors thank the efficiency and energy system research team of Alioune Diop University of Bambey (Senegal), and the Laboratory of Water, Energy, Environment and Industrial Processes, Cheikh Anta Diop University of Dakar, ESP, Dakar, Senegal.

\section{REFERENCES}

[1] I. E. Agency, "World Energy Investement," 2018.

[2] E. hadji M. Ndiaye, A. Ndiaye, M. Faye, and S. Gueye, "Intelligent Control of a Photovoltaic Generator for Charging and Discharging Battery Using Adaptive Neuro-Fuzzy Inference System," Int. J. Photoenergy, vol. 2020, 2020.

[3] O. Ben Belghith, L. Sbita, and F. Bettaher, "MPPT Design Using PSO Technique for Photovoltaic System Control Comparing to Fuzzy Logic and P \& O Controllers," Energy Power Eng., vol. 8, pp. 349-366, 2016.

[4] B. Bendib, F. Krim, H. Belmili, M. F. Almi, and S. Boulouma, "Advanced Fuzzy MPPT Controller for a stand-alone PV system," Energy Procedia, vol. 50, pp. 383-392, 2014.

[5] M. Nabipour, M. Razaz, S. G. H. Seifossadat, and S. S. Mortazavi, "A new MPPT scheme based on a novel fuzzy approach," Renew. Sustain. Energy Rev., vol. 74, no. February, pp. 1147-1169, 2017. 
[6] P. Kofinas, A. I. Dounis, G. Papadakis, and M. N. Assimakopoulos, "An Intelligent MPPT controller based on direct neural control for partially shaded PV system," Energy Build., vol. 90, pp. 51-64, 2015.

[7] E. hadji M. Ndiaye, A. Ndiaye, and M. Faye, "Experimental Validation of PSO and NeuroFuzzy Soft-Computing Methods for Power Optimization of PV installations," in 8th IEEE International Conference on Smart Grid, 2020, pp. 189-207.

[8] Z. Yao, L. Xiao, and J. M. Guerrero, "Improved control strategy for the three-phase grid-connected inverter," IET Renew. Gener., vol. 9, no. 3, pp. 587-592, 2015.

[9] A. Ndiaye, L. Thiaw, and G. Sow, "Application of new modeling and control for grid connected photovoltaic systems based on artificial intelligence," J. Electr. Electron. Eng. Res., vol. 7, no. 1, pp. 1-10, 2015.

[10] D. Gueye, A. Ndiaye, and F. Mactar, "Design Methodology of Novel PID for Efficient Integration of PV Power to Electrical Distributed Network," Int. J. Smart Grid, vol. 2, no. 1, 2018.

[11] N. Hamrouni, M. Jraidi, A. Dhouib, and A. Cherif, "Design of a command scheme for grid connected PV systems using classical controllers," Electr. Power Syst. Res., vol. 143, pp. 503-512, 2017.

[12] N. F. Guerrero-Rodriguez, A. B. Rey-Boué, and E. Reyes-Archundia, "Overview and comparative study of two control strategies used in 3-phase grid- connected inverters for renewable systems," Renew. energy Focus, vol. 20, no. 00, 2017.

[13] L. Ma, W. Ran, T. Q. Zheng, and S. Member, "Modeling and Control of Three-Phase GridConnected Photovoltaic Inverter," no. 2, pp. 2240-2245, 2010.

[14] B. Long, L. Huang, H. Sun, Y. Chen, F. Victor, and K. To, "An intelligent dc current minimization method for transformerless grid-connected photovoltaic inverters," ISA Trans., no. xxxx,
2018.

[15] C. MAHAMAT, M. PETIT, F. COSTA, and R. MAROUANI, "Balanced Active and Reactive Control Applied to a Grid Connected Five Level Inverter," Int. J. Adv. Comput. Sci. Appl., vol. 8, no. $10,2017$.

[16] F. Lin, K. Lu, and T. Ke, "Probabilistic Wavelet Fuzzy Neural Network based reactive power control for grid-connected three-phase PV system during grid faults," Renew. Energy, vol. 92, pp. 437-449, 2016.

[17] S. Vinnakoti and V. R. Kota, "ANN based control scheme for a three-level converter based unified power quality conditioner," J. Electr. Syst. Inf. Technol., vol. 5, no. 3, pp. 526-541, 2018.

[18] A. Kusagur, S. F. Kodad, and S. Ram, "Modelling \& simulation of an ANFIS controller for an AC drive," World J. Model. Simul., vol. 8, no. 1, pp. 36-49, 2012.

[20] R. Pavan Kumar Naidu and S. Meikandasivam, "ICM based ANFIS MPPT controller for grid connected photovoltaic system," Int. J. Eng. Technol., vol. 7, no. 3, pp. 1508-1513, 2018.

[20] N. El hadji Mbaye, N. Alphousseyni, M. Faye, and A. Thiam, "Design and implementation of NeuroFyzzy command of three-phase inverter connected to the electricity grid."

[21] M. A. Enany, M. A. Farahat, and A. Nasr, "Modeling and evaluation of main maximum power point tracking algorithms for photovoltaics systems," Renew. Sustain. Energy Rev., vol. 58, pp. 1578-1586, 2016.

[22] P. K. Gayen and A. Jana, "An ANFIS based improved control action for single phase utility or micro-grid connected battery energy storage system," J. Clean. Prod., vol. 164, pp. 1034-1049, 2017.

[23] N. Altin, "dSPACE based adaptive neuro-fuzzy controller of grid interactive inverter," vol. 56, pp. 130-139, 2012. 


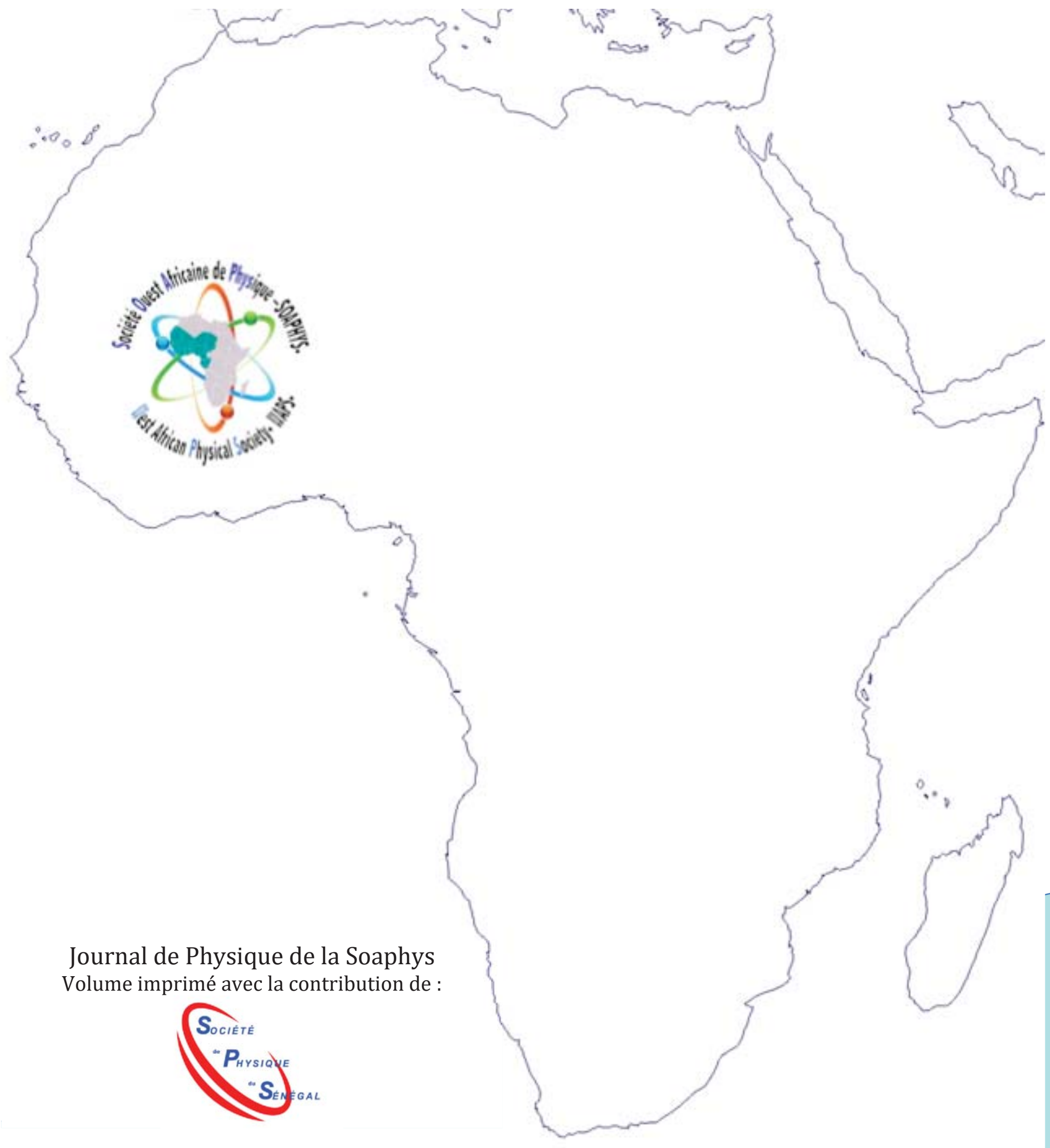

